\title{
SARS-CoV-2 will constantly sweep its tracks: a vaccine containing CpG motifs in 'lasso' for the multi-faced virus
}

\author{
V. V. Oberemok ${ }^{1}$ K. V. Laikova ${ }^{1} \cdot$ K. A. Yurchenko ${ }^{1}$ N. A. Marochkin ${ }^{1}$ - I. I. Fomochkina ${ }^{1}$ - A. V. Kubyshkin ${ }^{1}$ (I)
}

Received: 13 May 2020 / Revised: 28 June 2020 / Accepted: 6 July 2020 / Published online: 12 July 2020

(c) Springer Nature Switzerland AG 2020

\begin{abstract}
During the current COVID-19 pandemic, the global ratio between the dead and the survivors is approximately 1 to 10 , which has put humanity on high alert and provided strong motivation for the intensive search for vaccines and drugs. It is already clear that if we follow the most likely scenario, which is similar to that used to create seasonal influenza vaccines, then we will need to develop improved vaccine formulas every year to control the spread of the new, highly mutable coronavirus SARS-CoV-2. In this article, using well-known RNA viruses (HIV, influenza viruses, HCV) as examples, we consider the main successes and failures in creating primarily highly effective vaccines. The experience accumulated dealing with the biology of zoonotic RNA viruses suggests that the fight against COVID-19 will be difficult and lengthy. The most effective vaccines against SARS-CoV-2 will be those able to form highly effective memory cells for both humoral (memory B cells) and cellular (cross-reactive antiviral memory T cells) immunity. Unfortunately, RNA viruses constantly sweep their tracks and perhaps one of the most promising solutions in the fight against the COVID-19 pandemic is the creation of 'universal' vaccines based on conservative SARS-CoV-2 genome sequences (antigen-presenting) and unmethylated CpG dinucleotides (adjuvant) in the composition of the phosphorothioate backbone of single-stranded DNA oligonucleotides (ODN), which can be effective for long periods of use. Here, we propose a SARS-CoV-2 vaccine based on a lasso-like phosphorothioate oligonucleotide construction containing $\mathrm{CpG}$ motifs and the antigen-presenting unique ACG-containing genome sequence of SARS-CoV-2. We found that CpG dinucleotides are the most rare dinucleotides in the genomes of SARS-CoV-2 and other known human coronaviruses, and hypothesized that their higher frequency could be responsible for the unwanted increased lethality to the host, causing a 'cytokine storm' in people who overexpress cytokines through the activation of specific Toll-like receptors in a manner similar to TLR9-CpG ODN interactions. Interestingly, the virus strains sequenced in China (Wuhan) in February 2020 contained on average one $\mathrm{CpG}$ dinucleotide more in their genome than the later strains from the USA (New York) sequenced in May 2020. Obviously, during the first steps of the microevolution of SARS-CoV-2 in the human population, natural selection tends to select viral genomes containing fewer $\mathrm{CpG}$ motifs that do not trigger a strong innate immune response, so the infected person has moderate symptoms and spreads SARS-CoV-2 more readily. However, in our opinion, unmethylated $\mathrm{CpG}$ dinucleotides are also capable of preparing the host immune system for the coronavirus infection and should be present in SARS-CoV-2 vaccines as strong adjuvants.
\end{abstract}

Keywords SARS-CoV-2 $\cdot$ COVID-19 pandemic $\cdot$ Phosphorothioate oligonucleotides $\cdot$ CpG motif $\cdot$ Vaccine

Vaccines and drugs help mankind reduce the effects of natural selection when meeting and dealing with pathogens. On the one hand, this slows down the process of adaptation of

Responsible Editor: John Di Battista.

A. V. Kubyshkin

kubyshkin_av@mail.ru

1 V.I. Vernadsky Crimean Federal University, Simferopol, Russia the human population to negative environmental factors; on the other hand, we save that which is most valuable- the life of each individual person. Nevertheless, it must be recognized that drugs and vaccines only delay the fatal meeting of the causative agent of the disease with those who are pathogen-sensitive or their genetic descendants. Natural selection is merciless-only the fittest survives. Since no one knows for sure which pathogen he or she will be sensitive to, everyone expects that at the nearest pharmacy a person will find, at the right time, a medicine that will save 
his or her life. Obviously, this is not what happens. Today, during the sudden COVID-19 pandemic, we understand how fragile our habitual way of life has turned out to be. In fact, we are at the mercy of pure natural selection, and we are not able to oppose it with any effective vaccine or drug. Nevertheless, a sufficiently large number of research groups have already joined the race to create vaccines and drugs against the SARS-CoV-2 virus, which in the next few years will significantly slow down the effect of natural selection. In turn, weakened by vaccines and drugs, natural selection will continue to work and COVID-19 will morph into a disease with mild symptoms in the years to come. However, at this moment in time, during the exponential growth of the pandemic, the virus is aggressive and needs to be restrained as soon as possible.

SARS-CoV-2 is positive-sense, single-stranded RNA betacoronavirus from the Coronaviridae family. Genomic alignments suggest that the SARS-CoV-2 from the genus Betacoronavirus may be the result of a recombination of genetic material from two different viruses, one similar to the Chinese horseshoe bat virus and the other closer to the pangolin virus [1]. In fact, only two scenarios will occur simultaneously in the very near future: people who are genetically resistant to the virus will get sick, recover, and develop immunity, while people who are sensitive to the virus will need drugs and vaccines, which will have to be researched and developed if they are to recover. Since SARS-CoV-2 mutates constantly and more frequently than other RNA viruses (coronaviruses possess the longest genomes of all known RNA viruses, so more errors are made when they are copied; also, viral RNA-dependent RNA polymerases do not have a proofreading nuclease activity), it is likely that many new strains of the virus will appear and this will be a problem for creating vaccines. Still, vaccines are arguably the most powerful medical intervention in the fight against infectious diseases [2]. Generally, all vaccines work on the same basic principle. They present part or all of the pathogen to the human immune system, usually in the form of injections and in low doses, to induce the system to produce antibodies to the pathogen and activate induction of cross-reactive antiviral T cells, particularly the cytotoxic $\mathrm{T}$ lymphocytes that can kill virus-infected cells. Specific $\mathrm{T}$ lymphocytes and antibody-producing plasma cells (B cells) represent a kind of immune memory, which, once a virus is detected, can be quickly mobilized again if a person is exposed to the virus in its natural form. Traditionally, adjuvants (aluminum salts, squalene-in-water emulsions, imidazoquinoline derivatives, saponins, synthetic phophorothioate-linked DNA oligonucleotides with optimized $\mathrm{CpG}$ motifs, etc.) have been used in vaccines to increase the magnitude of an adaptive response to a vaccine, based on antibody titer or ability to prevent infection. However, a second role for adjuvants has become increasingly important: guiding the type of adaptive response to produce the most effective forms of immunity for each specific pathogen [3, 4]. Previous studies on several animal coronaviruses also suggest that not only humoral but also cellular, immunity plays a role in protecting against virus infection $[5,6]$. Classic methods involve taking a whole virus, weakening or killing it, then injecting its remains into a person's body.

For the human population, COVID-19 is the third significant coronavirus infection to occur in the twenty-first century, following severe acute respiratory syndrome (SARS) in 2002-2003 and Middle East respiratory syndrome (MERS) in 2012, which have not stopped yet. Since 2012 until 29 February 2020, the total number of laboratory-confirmed MERS-CoV infection cases reported globally to WHO is 2538 with 871 associated deaths. But while those outbreaks alerted the world to the virulent potential of the coronavirus family, SARS fizzled out faster than a vaccine could make its way through clinical trials, and MERS was not viewed seriously enough to generate sustained funding for vaccine developers. This despite the fact that the 2002 SARS and 2012 MERS outbreaks, both caused by close relatives of the new coronavirus, were warning shots that claimed approximately 774 and 871 lives, respectively.

One major hitch in developing a COVID-19 vaccine is that no medically proven predecessor exists for any type of human coronavirus. Only a small number of SARS-CoV vaccines made it to Phase I clinical trials before funding dried up because the virus was eradicated from the human population through non-pharmaceutical interventions when the case numbers were still small. The first vaccine tested in a clinical trial is made from the inactivated form of SARS$\mathrm{CoV}$. Several live attenuated, genetically engineered, or vector vaccines encoding the SARS-CoV spike (S) protein have been tested in pre-clinical studies. These vaccine candidates are effective in terms of eliciting protective immunity in the vaccinated animals. However, the use of whole virus or full-length $\mathrm{S}$ protein-based immunogens in humans should be approached with caution, because their use could induce harmful immune or inflammatory responses. Some authors have proposed the use of the receptor-binding domain (RBD) of SARS-CoV S protein (residues 318-510) in the development of a safe and effective subunit SARS vaccine. This functional domain, responsible for mediating virus-receptor binding, is also a major neutralization determinant of SARS-CoV [7]. These trials, performed using an inactivated virus vaccine and a spike-based DNA vaccine, have produced encouraging results; in addition to being safe, the vaccines induced neutralizing antibody titers $[8,9]$. The structure of the S protein of SARS-CoV-2 was solved in record time at high resolution, contributing to our understanding of this vaccine target [10, 11]. It has been shown that some of the neutralizing monoclonal antibodies isolated against SARS-CoV, such as CR3022 [12, 13], 
can cross-react with the receptor-binding domain of SARS$\mathrm{CoV}-2$. This suggests that SARS-CoV vaccines might crossprotect against SARS-CoV-2. However, because these vaccines have not been developed further than Phase I, they are currently not available for use. MERS-CoV vaccines are unlikely to induce strong cross-neutralizing antibodies to SARS-CoV-2 because of the phylogenetic distance between the two viruses. Nevertheless, we can still learn a lot from these vaccines about how to move forward with SARS-CoV-2 vaccine design [14].

Vaccines are usually developed on the basis of certain virus strains, as follows. The most well-known example is influenza vaccines. Influenza viruses belong to the Orthomyxoviridae family and are characterized by segmented, negative-strand RNA genomes. Infection with influenza viruses is a constant challenge, burdening people's health and economies worldwide every year. These infections cause epidemics that can become pandemics, affecting 5-30\% of the global population annually, and are responsible for millions of hospitalizations and hundreds of thousands of deaths each year [15]. Natural reservoirs exist for influenza, infecting a wide range of animal hosts. These include wild aquatic birds, the natural reservoir for the influenza A virus, and pigs. Since pigs can become infected with influenza B virus, they may provide a natural reservoir for the virus [16]. While influenza, like COVID-19, causes morbidity among all ages, those most vulnerable to its serious complications, such as pneumonia, are the elderly $[17,18]$. At the present time, the two available types of influenza vaccines are administered by different routes: parenteral inactivated influenza vaccines (IIV), delivered by injection, and intranasal live attenuated influenza vaccines (LAIV). LAIV mimic the course of natural infections and thus induce a stronger immune response than IIV [19]. Intransal administration of LAIV produces a variety of adaptive immune responses, including serum antibodies and mucosal and cell-mediated immunity [20]. Based on data gathered by the Global Influenza Surveillance and Response System (GISRS), a partnership of 141 national influenza centers in 111 countries, six WHO collaborating centers, and four WHO essential regulatory laboratories, WHO updates the composition of influenza vaccines (both IIV and LAIV) annually. The WHO GISRS continually collects and analyses global influenza virus samples. By monitoring circulating influenza A and B viruses for how recently they have occurred and with what frequency, changes can be made to the components in the vaccines slated for the upcoming influenza season in both the northern and southern hemispheres [21]. Current influenza vaccination strategy induces cells to produce antibodies directed against the surface antigens of these viruses, with the main targets being the surface glycoprotein antigens hemagglutinin (HA) and neuraminidase (NA). The amino acid sequences encoding $\mathrm{HA}$ and NA are hypervariable, as a consequence of antigenic drift or shift, respectively. This characteristic makes them responsible in large part for both epidemic and pandemic influenza outbreaks [15]. In addition, these frequent changes to the surface antigens of influenza viruses allow them to avoid antibody-mediated immunity. On the other hand, it has been shown that cytotoxic T-lymphocyte populations, when directed against the internal antigens of influenza A virus, demonstrate a broad cross-reactivity with the influenza virus subtypes [22]. Both IIV and LAIV vaccines have a history of safe use in children and adults. However, both can cause adverse events and/or rare adverse events, some more prevalent in children, others more likely to occur in adults [23]. Each year, necessary changes are made to the formulation of influenza vaccines and when they are administered. Factors that affect those being vaccinated, both genetic and environmental, are difficult, if not impossible, to control. For these reasons, even though vaccines undergo strict monitoring before authorization, the possible occurrence of adverse effects, such as narcolepsy [24], cannot be completely eliminated. Consequently, annual post-licensure vaccine safety surveillance is fundamental [25]. For all of these reasons, no universal influenza vaccine is yet available against all influenza virus subtypes and seasonal influenza vaccines require annual updates. The lack of preventive vaccines for clinical use in humans against such viruses makes emerging influenza and coronaviruses a serious global threat [26]. Currently, available vaccines keep deaths from influenza relatively under control. However, when any influenza virus lineage emerges in a novel mammalian host population, the threat of a direct or indirect pandemic is a real risk [27].

The creation of vaccines for seasonal influenza viruses is justified because they work, but for some other RNA viruses, this is not so. The human immunodeficiency virus, types 1 and 2 (HIV-1 and HIV-2), is an example of a zoonotic infection that has spread all over the world without being stopped. At the moment, approximately 38 million people have been infected with HIV, but there is not a single successful vaccine able to effectively contain the HIV pandemic [28]. Both types of HIV are the result of multiple cross-species transmissions that occurred when simian immunodeficiency viruses (SIV) naturally infected African primates [29]. The human immunodeficiency virus (HIV), which consists of two identical negative-sense singlestranded RNA molecules, belongs to the genus Lentivirus in the Retroviridae family, subfamily Orthoretrovirinae [28]. Attempts to develop a safe and effective HIV vaccine have been hindered by the difficulty in clearly defining the specific immune responses responsible for preventing infection and limiting disease progression. Since early attempts to use vaccines to induce neutralizing antibodies ended in disappointment, recent research efforts have focused on vaccines that induce T-cell immunity. The belief that the specific antiviral CD8 $\mathrm{T}$ lymphocyte response is crucial for immune 
control of viral replication has provided an important facet for ongoing efforts to develop effective vaccines against HIV. Unfortunately, while the actions of T cells are known to limit HIV and other viral infections after the infection has already occurred, their role, if any, in protecting against initial infection is much less clear [2]. HIV-1 is highly mutable. This, combined with its complex structure and life cycle, has placed further obstacles in the path to developing an effective vaccine. The virus is a master of obfuscation. For instance, it uses variable glycosated residues to camouflage the conserved receptor- and coreceptor-binding sites on the viral envelope (Env) glycoproteins engaged in the virus's attachment and fusion to host membrane receptors [30]. In addition, the conserved sites are thermostably concealed [31]. These are just two of the features that allow the virus to nimbly evade detection by cross-reactive antibody ( $\mathrm{Ab}$ )producing $\mathrm{B}$ cells that recognize conserved sites. As a part of its life cycle, HIV-1 is able to integrate into its host's genome, forming a latent provirus that escapes immune recognition owing to the absence of significant protein expression [32]. Neutralizing antibodies (NAb) typically play a key role in controlling viral infections and contribute to the protective effect of many successful vaccines. Compelling data gathered using experimental animal models have demonstrated that NAb can prevent HIV-1 acquisition; however, no similar data exists for humans and the role of NAb in controlling established infection in humans is also limited. It is clear that HIV-specific NAb drives the evolution of the HIV-1 envelope glycoprotein within an infected individual. The ability of the virus to evade immune selection may be the main reason HIV-1 NAb exert limited control during infection. Attempts to define NAb capable of providing a broad spectrum of protection against diverse circulating HIV-1 strains have encountered the difficulties posed by the extraordinarily antigenic diversity of HIV-1 [33]. Reports that the breadth and potency of humoral responses are higher in subtypes $\mathrm{C}$ and $\mathrm{A}$ than in subtype $\mathrm{B}$ infections provides evidence that viral genetic subtype may also be important $[34,35]$. In addition to its talents for concealment, the virus can also make mistakes. The high error rate of the reverse transcriptase [36], combined with the rapid turnover of plasma virions [37], further hinders the development of an effective vaccine by providing a dizzying range of variants from which to select and escape from both cellular and humoral immune responses [38, 39]. At present, at least 12 recognized HIV-1 genetic subtypes are known to exist in humans. Each of these subtypes has rapidly diversified to yield intersubtype recombinants $[40,41]$ that present an even greater challenge in the development of a universal HIV vaccine.

Another 'multi-headed beast' sweeping its tracks is the hepatitis $\mathrm{C}$ virus (HCV). $\mathrm{HCV}$ is a positive-sense single-stranded RNA virus of the Flaviviridae family [42].
Although the zoonotic origins of $\mathrm{HCV}$ in humans remain unclear, recent and direct cross-species transmission from horses to dogs appears plausible [43]. Highly diverse HCVrelated viruses have also been detected in bats and rodents [44], in cattle [45], and in black-and-white colobus monkeys [46]. There is good news in the form of direct-acting antivirals (DAA) against the hepatitis $\mathrm{C}$ virus (HCV) infection, which have been shown to achieve a complete cure in $>95 \%$ of cases $[47,48]$. It has been suggested that DAA have the potential to eliminate an infection that affects more than 71 million individuals worldwide [49]. This is particularly important because many individuals do not seek treatment for constant hepatitis $\mathrm{C}$ because they are unaware that they are infected. Sadly, it is often a long time after the initial infection, when hepatitis $\mathrm{C}$ has precipitated serious health issues, that these individuals look for help. It is estimated that only $5 \%$ of HCV cases worldwide are diagnosed [50, 51]. This is one reason that the development of vaccines that protect against persistent $\mathrm{HCV}$ infection remain a public health priority. Without access to vaccines that can limit viral transmission, even the broad use of highly effective DAA is unlikely to achieve HCV elimination. In addition, DAA treatment does not protect against reinfection, further underscoring the need for an effective vaccine [52]. Current preclinical and clinical trials are being carried out for two vaccines that target either the antibody or the $\mathrm{T}$ cell response. The next generation of vaccines is likely to involve a combination of these two strategies. The first vaccine contains a recombinant form of the virus envelope glycoproteins gpE1 and gpE2, aimed at inducing neutralizing antibodies and CD4 helper T cells [53, 54]. The second vaccine is vector-based and encodes nonstructural (NS) proteins of the virus (NS3-NS5) using chimpanzee adenovirus priming and a modified vaccinia Ankara (MVA) boost. These represent two of the most promising strategies: production of broadly neutralizing antibodies (bNAb) to neutralize the infectivity of the virus and generation of potent virus-specific CD4 and CD8 T cells to eliminate infected hepatocytes [55]. Multiple studies of $\mathrm{HCV}$ in humans and chimpanzees have provided strong evidence for the kinetic association between spontaneous viral clearance and the induction of a broad, sustained group of HCV-specific CD4 and CD8 T cells [56]. As it turns out, these $\mathrm{T}$ cells are polyfunctional, producing multiple cytokines and effector functions [57]. For instance, as the infection is being cleared, virus-specific T cells develop a memory $\mathrm{T}$ cell phenotype that upregulates cell surface expression of the IL-7 receptor CD127 [58-60]. If the virus persists, CD8 $\mathrm{T}$ cells that recognize intact epitopes (i.e., epitopes that have not mutated) become exhausted and express exhaustion markers such as programmed death 1 (PD1), T-cell immunoglobulin and mucin domain-containing-3 (Tim-3), cytotoxic T-lymphocyte protein 4 (CTLA4), 2B4, CD160, KLRG1, T-cell immunoreceptor with Ig 
and ITIM domains (TIGIT), and CD39 [56, 61]. There is an increasing amount of evidence that the specificity and potency of the early antibody response can influence the acute infection outcome and that neutralizing antibodies seem to play a part in controlling HCV during chronic infection [62]. In particular, it is worth noting the data from studies showing that bNAb isolated from chronically infected and spontaneously resolved individuals have the capacity to block infectivity in mouse models of $\mathrm{HCV}$ infection, further emphasizing the important protective effect of the antibody response [63-65].

Thus, in one way or another, all vaccines aimed at preventing zoonotic RNA viruses are focused on producing specific antibodies and activating cytotoxic $\mathrm{T}$ lymphocytes that can cause the death of virus-infected cells. In general, the lack of effective vaccines against some RNA viruses, such as coronaviruses, HIV, and HCV, can be explained by the large number of mutations that occur during replication, as well as weak antibody activity. To some extent, the slow progress in the development of $\mathrm{HCV}$ and SARS coronavirus vaccines is also due to the lack of sufficient funding and the advent of highly effective DAA in the case of HCV. Nevertheless, a large number of RNA viruses of zoonotic origin will always carry with them the danger of new pandemics; the creation of vaccines can help humans be better prepared to meet them. Ideal vaccines are those that will be effective for the vast majority of people and against most of the strains of the target circulating RNA virus. One promising strategy is to create vaccines based on conservative sequences of viral genomes using oligonucleotides. Despite the impressive success of currently approved adjuvants for generating immunity to viral and bacterial infections, there remains a need for improved adjuvants that enhance protective antibody responses, especially in populations that respond poorly to current vaccines. Today, the larger challenge is to develop vaccines that generate strong $\mathrm{T}$ cell immunity with purified or recombinant vaccine antigens. Oligonucleotides can be used as both antigens and adjuvants.

Several studies have shown that oligonucleotides can improve the efficacy of vaccines, either by inducing antigen modification (i.e., by enhancing expression of immunogenic molecules) or by targeting certain components of the host immune system to achieve the desired immune response. However, despite their extensive use, problems such as insufficient stability and low cellular delivery have not been sufficiently resolved to achieve effective and safe oligonucleotide-based vaccines [66]. For many years, nucleic acids and short nucleotide molecules have been used as vaccine components. Their use has ranged from DNA $[67,68]$ or RNA vaccines [69, 70], to oligonucleotide sequences containing unmethylated cytidine phosphate guanosine $(\mathrm{CpG})$ motifs with significant immunostimulatory (adjuvant) properties [71, 72]. More recently, strategies that manipulate the expression of genes controlling the immune response or the expression of antigens of interest are being used to improve immunogenicity and vaccine efficacy. This line of research has a history of more than 30 years; in one of the first experiments, when spleen cells from BALB/c mice were incubated with the nucleic acid fraction from different bacteria, the natural killer (NK) activity of the cells was remarkably elevated and the cells produced factors that activated macrophages and inhibited viral growth. The factor that activated the macrophages was interferon (IFN)-gamma and the other factor, which inhibited viral growth, was IFNalpha/beta. However, the nucleic acid fraction from neither of the vertebrate cells showed any such activity. This report provided evidence for the first time that, while DNA from microorganisms and invertebrates could induce IFN, the DNA from vertebrates, and probably from plants as well, could not [73].

In 1995, Krieg et al. reported that unmethylated $\mathrm{CpG}$ dinucleotides (CpG ODN) within bacterial DNA activated host defense mechanisms that led in turn to innate and adaptive immune responses [74]. CpG ODN is a ligand of Tolllike receptor 9 (TLR-9) in antigen-presenting cells. Toll-like receptors (TLR) are a family of non-clonal pattern-recognition receptors that recognize conserved pathogen-associated molecular patterns (PAMP). Under homeostatic conditions, TLR discrimnate 'non-self' from 'self' in that they do not sense host-derived 'self-molecules' but become activated by PAMP during infection [75]. Ligand binding by TLR3, TLR7, TLR8, and TLR9 occurs in the acidic environment of the endosome [76] and causes cellular activation, presumably by stabilizing preformed TLR dimers or inducing TLR-dimer formation. CpG ODN/TLR-9 interaction induces an innate immune response that promotes the subsequent development of adaptive immunity [71, 77]. Their utility as vaccine adjuvants has been evaluated in different clinical trials and the results indicate that $\mathrm{CpG}$ ODN augments the induction of vaccine-specific cellular and humoral responses [72]. In 2017, the FDA approved HEPLISAV-B, the first vaccine with a $\mathrm{CpG}$ ODN as an adjuvant, for hepatitis $\mathrm{B}$ vaccines [78]. However, it has also been reported that $\mathrm{CpG}$ ODN can induce high levels of pro-inflammatory cytokines, with the potential risk of developing or worsening autoimmune diseases and systemic inflammatory response syndrome (SIRS) [79, 80].

TLR9 agonists have demonstrated a substantial potential as vaccine adjuvants, and as mono- or combination therapies for the treatment of cancer and infectious and allergic diseases. Commonly referred to as $\mathrm{CpG}$ oligodeoxynucleotides (ODN), TLR9 agonists directly induce the activation and maturation of plasmacytoid dendritic cells and enhance differentiation of B cells into antibody-secreting plasma cells. Preclinical and early clinical data support the use of TLR9 agonists as vaccine adjuvants, where they can enhance both the humoral and cellular responses to diverse 
antigens [77]. When used as vaccine adjuvants, $\mathrm{CpG}$ ODN improve the function of professional antigen-presenting cells and boost the generation of humoral and cellular vaccinespecific immune responses. These effects are optimized by maintaining the ODN and the vaccine in close proximity. The adjuvant properties of CpG ODN are observed when administered either systemically or mucosally, and persist in immunocompromised hosts. Preclinical studies indicate that $\mathrm{CpG}$ ODN improve the activity of vaccines targeting infectious diseases and cancer. Clinical trials demonstrate that $\mathrm{CpG}$ ODN have a good safety profile and increase the immunogenicity of co-administered vaccines [71].

The majority of studies carried out previously in SARSCoV-infected humans and animals pointed to a dysregulated/exuberant innate response as the leading contributor to SARS-CoV-mediated pathology. Almost two decades after the 2002-2003 SARS epidemic, we still do not have any approved preventive or therapeutic agents available with which to respond to the re-emergence of SARS-CoV or other related viruses. A strong neutralizing antibody response generated against the spike (S) glycoprotein of SARS-CoV is completely protected in the susceptible host. However, neutralizing antibody titers and the memory B cell response are short lived in SARS-recovered patients and the antibody will only target the primary homologous strain. Follow-up studies from patients who recovered from SARS suggest that the SARS-CoV-specific antibody response is fleeting. In these patients, the SARS-CoV-specific IgM and IgA response lasted less than 6 months, while the virus-specific IgG titer peaked 4 months post-infection and declined markedly after 1 year. Despite the lack of virus-specific memory B cell response, SARS-CoV-specific memory T cells persist in SARS-recovered patients for up to 6 years post-infection. Consistent with the results from these human studies, results from animal studies also suggest that strong virus-specific $\mathrm{T}$ cell responses are required to protect mice from lethal SARS-CoV-MA15 infection. Future vaccine interventions should, therefore, consider strategies that enhance the $\mathrm{T}$ cell response to provide a robust long-term memory. Since tissue-resident memory $\mathrm{T}$ cells provide better protection, boosting both local and systemic memory $\mathrm{T}$ cell responses would be a more useful strategy than either of these interventions alone. Although the amount of data available on virus-specific memory $\mathrm{T}$ cell responses to emerging coronaviruses is limited, existing studies indicate that lung resident virus-specific memory CD8 $\mathrm{T}$ cells provide substantial protection following SARS-CoV challenge. These studies suggest a potential role for virus-specific memory $\mathrm{T}$ cells in broad and long-term protection against SARS-CoV infection. This is important as the response of neutralizing Abs and memory B cells to SARS-CoV declines significantly 1-2 years post-infection; in addition, these responses are strain specific [81]. Taken together, these data clearly suggest that the CpG ODN/TLR-9 interaction induces a strong innate immune response that promotes the subsequent development of an adaptive immunity triggered by the production of $\mathrm{T}$ helper cells one and pro-inflammatory cytokines.

With advancing age, both humans and animals become highly susceptible to SARS-CoV and other respiratory virus infections. Such an age-dependent increase in susceptibility is associated with a significant reduction in the magnitude of the virus-specific T cell response [82-84]. Young C57BL/6 mice (6 weeks of age) generate a SARS-CoV-specific CD8 T cell response that is approximately eightfold greater than that observed in 12-month-old mice [85]. Virus-specific CD8 T cells play a critical role in viral clearance; $\mathrm{CD} 4 \mathrm{~T}$ cells provide the necessary support for the antiviral function of the CD8 T cells [86]. Generally, results suggest that the role of virus-specific primary $\mathrm{CD} 4$ and $\mathrm{CD} 8 \mathrm{~T}$ cell responses to respiratory or other coronavirus infections are both virus and mouse strain dependent [81]; in other words, they depend on the genetic component of the host-virus relationship. Eventually, in the absence of vaccines and drugs, natural selection will rapidly lead to the survival of only genetically resistant individuals in a host population.

At this juncture, we propose a SARS-CoV-2 aerosolbased vaccine based on a lasso-like phosphorothioate oligonucleotide construction containing $\mathrm{CpG}$ motifs and antigen-presenting unique sequence (APUS) (Fig. 1). Aerosol immunization seems to be a promising method of vaccination [87, 88], including as it does aerosolized delivery of nucleic acids optimized for lung uptake [89] and nasal spray [90]. Several independent studies have now demonstrated that the dependence on CpG motifs for TLR9 activation is

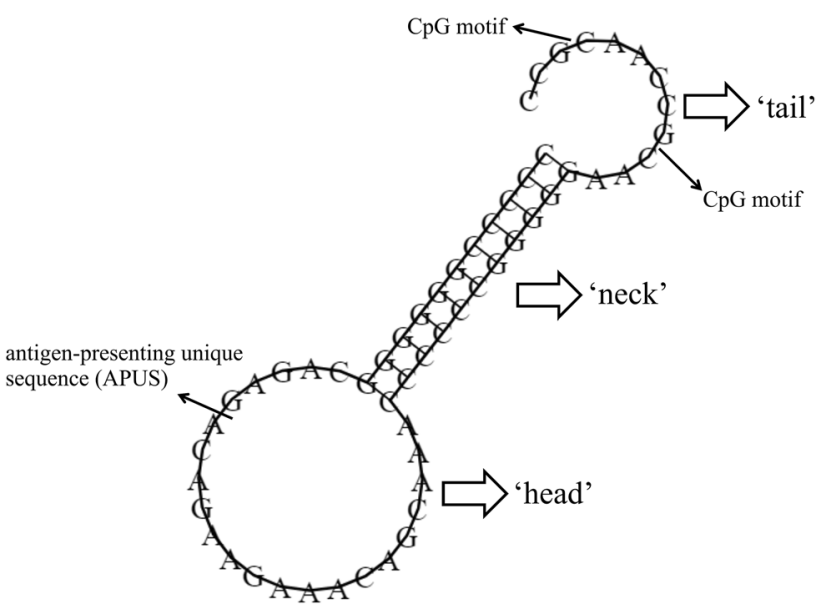

Fig. 1 Structure of a SARS-CoV-2 vaccine based on a lasso-like phosphorothioate oligonucleotide construction containing $\mathrm{CpG}$ motifs and antigen-presenting unique ACG-containing genome sequence of SARS-CoV-2 (performed by RNAfold WebServer; https ://rna.tbi.univie.ac.at) 
restricted to synthetic phosphorothioate oligodeoxynucleotides (PS-ODN), and that natural phosphodiester oligodeoxynucleotides (PD-ODN) bind and activate TLR9 via the 2 ' deoxyribose backbone in a sequence-independent manner [91-95]. Indeed, further control can be achieved through recognition of cytosine methylation, which acts as a negative determinant, i.e., its presence in mammalian DNA prevents the triggering of TLR9.

In the proposed construction, the main role of the antigenpresenting part of the vaccine will be played by the phosphorothioate oligonucleotides found on the APUS region (Fig. 1). Phosphorothioate (PS) oligonucleotides, which contain a non-bridging sulfur, are the most widely studied oligonucleotides; compared to unmodified oligonucleotides, they possess higher solubility and nuclease stability, with improved membrane penetration. Nuclease stability is important because human lung fluid possesses DNase activity. This activity can be inhibited by the use of direct nuclease inhibitors, which enhance the uptake of oligonucleotide-based vaccines by cells [96] or through oligonucleotide modification. Therapeutic use of oligonucleotides is highly dependent upon their efficient uptake by cells. The literature contains many reports of experiments both in tissue culture and in vivo using a phosphorothioate backbone to generate antisense effects mediated by an RNase H-dependent mechanism. These data have led to the investigation of phosphorothioate oligonucleotides in therapeutic clinical trials [97]; it has also been demonstrated that $\mathrm{CpG}$ motifs within phosphorothioate (PS)-modified DNA effectively drive Tolllike receptor 9 (TLR9) activation [98].

We found that $\mathrm{CpG}$ dinucleotides are the most rare dinucleotides in the genomes of SARS-CoV-2 and other known human coronaviruses (Table 1), and hypothesized that their higher frequency could cause the unwanted increased lethal effect on the host, resulting in a 'cytokine storm' in people prone to overexpress cytokines through the activation of specific Toll-like receptor interactions with single-stranded RNA in a manner similar to those of TLR9-CpG ODN interactions. Most RNA viruses that infect mammals and other vertebrates profoundly suppress $\mathrm{CpG}$ dinucleotide frequencies [99]. The functional nature of this apparent selection against $\mathrm{CpG}$ dinucleotides operating on both host and viral cytoplasmic RNA sequences remains unexplained.

However, it has been frequently hypothesized that recognition of $\mathrm{CpG}$ motifs is part of an as yet uncharacterized 'self-non-self' recognition system coupled to an innate immunity [100]. This may be functionally and perhaps evolutionarily related to the Toll-like receptor 9 that recognizes non-methylated CpG dinucleotides in DNA sequences [101, 102]. Atkinson et al. decided to investigate the roles played by the various components of the innate immune system in recognizing dinucleotides and recruiting antiviral defenses. Their interest was caught when they observed that elevated frequencies of both $\mathrm{UpA}$ and $\mathrm{CpG}$ attenuated viral replication, whereas frequencies lower than those of native viral sequences enhanced replication [99]. However, our thinking goes in the other direction: natural selection aims to strengthen the genotypes of RNA viruses with fewer $\mathrm{CpG}$ dinucleotides, because otherwise, a strong 'cytokine storm' is unleashed in people prone to overexpress cytokines, causing the death of the host, which for the virus presents a developmental impasse. Any virus that completely eliminates its host population finds itself in an evolutionary dead end since viruses are obligate intracellular parasites. A certain balance of power exists in the virus-host relationship; to an extent, all of its participants remain 'gentlemen' and provide their opponents with the opportunity to survive and reproduce. The system sacrifices units, but the community is saved. Dinucleotides appearing and disappearing during the microevolution of the coronavirus $\mathrm{CpG}$ apparently help to adjust (more or less) the optimal level at which the parasite disseminates when the virus replicates, resulting in a moderate number of deaths of individuals in the host population. Since SARS-CoV-2 appeared only recently in the human population, in the near future we will see just such an adjustment as the number of $\mathrm{CpG}$ oligonucleotides changes in the direction optimal for the virus to replicate. Interestingly, the genome of virus strains sequenced in China (Wuhan) on February 11, 2020 contained on average $1 \mathrm{CpG}$ dinucleotide more than was observed in later strains from the USA sequenced on May 6, 2020 (Table 2). Obviously, at the beginning of the microevolution of SARS-CoV-2 in

Table 1 Occurrence of various dinucleotides in the genomes of known human coronaviruses

\begin{tabular}{|c|c|c|c|c|c|c|c|c|c|c|c|c|c|c|c|c|}
\hline & CG & $\mathrm{CC}$ & GG & $\mathrm{GC}$ & UC & GA & $\mathrm{AG}$ & GU & $\mathrm{AC}$ & $\mathrm{CU}$ & $\mathrm{CA}$ & AA & $\mathrm{AU}$ & UA & UU & UG \\
\hline SARS-CoV-2 NC_045512.2 & 439 & 784 & 973 & 1168 & 1413 & 1612 & 1742 & 1990 & 2023 & 2081 & 2084 & 2169 & 2308 & 2377 & 2454 & 2589 \\
\hline SARS-CoV NC_004718.3 & 568 & 850 & 1072 & 1433 & 1553 & 1680 & 1752 & 1871 & 1979 & 2191 & 2206 & 1922 & 2236 & 2081 & 2207 & 2664 \\
\hline MERS-CoV NC_019843.3 & 711 & 973 & 1084 & 1490 & 1695 & 1472 & 1654 & 2180 & 1766 & 2309 & 1931 & 1727 & 2284 & 2302 & 2407 & 2704 \\
\hline HCoV-NL63 NC_005831.2 & 332 & 535 & 907 & 884 & 1147 & 1185 & 1280 & 2436 & 1363 & 1717 & 1345 & 1716 & 2380 & 2493 & 3171 & 2893 \\
\hline HCoV-HKU1 NC_006577.2 & 340 & 527 & 877 & 860 & 1248 & 1429 & 1531 & 2437 & 1194 & 1777 & 1184 & 1898 & 3093 & 3205 & 3428 & 2854 \\
\hline HCoV-OC43 NC_006213.1 & 485 & 701 & 1150 & 1327 & 1186 & 1626 & 1823 & 2411 & 1331 & 1758 & 1600 & 1925 & 2867 & 2794 & 2892 & 3056 \\
\hline HCoV-229E NC_002645.1 & 488 & 615 & 984 & 1165 & 1131 & 1399 & 1417 & 2241 & 1559 & 1727 & 1640 & 1782 & 2097 & 2034 & 2522 & 2900 \\
\hline
\end{tabular}


Table 2 Occurrence of $\mathrm{CpG}$ dinucleotides in the SARS-CoV-2 isolates from China $(n=7)$ and USA $(n=36)$ found in GenBank

\begin{tabular}{ll}
\hline Virus origin & $\begin{array}{l}\text { Occurence of } \\
\text { CpG dinucleo- } \\
\text { tide } \\
\text { mean } \pm \text { SE }\end{array}$ \\
\hline SARS-CoV-2 China, Wuhan, February 11, 2020 & $439.14 \pm 0.09$ \\
SARS-CoV-2 USA, New York, May 6, 2020 & $438.44 \pm 0.14 *$ \\
\hline
\end{tabular}

${ }^{*} p<0.01$

the human population, natural selection tends to favor viral genomes containing fewer $\mathrm{CpG}$ motifs so as not to trigger a strong innate immune response. Apparently, people who become infected with the virus have moderate symptoms and spread SARS-CoV-2 more readily. It is worth noting that the influenza A virus, which originated from an avian reservoir, has undergone a significant reduction in the number of CpG nucleotides since its introduction into humans [102]. This hypothesis is further reinforced by the fact that the $\mathrm{CpG}$ motif in an AU-rich oligonucleotide can significantly stimulate the immune response of plasmacytoid dendritic cells [100, 103].

In our 'lasso' construct, we placed the CpG motifs in the 'tail' region in the to 5'-purine-purine-unmethylated deoxycytosine-deoxyguanosine-pyrimidine-pyrimidine-3' position [104]. The 'neck' region of the construct features a double-stranded DNA region stabilized by 30 hydrogen bonds between 10 cytosines and 10 guanines. The doublestranded DNA 'neck' makes it possible to form a loop in the region of the antigen-presenting 'head'. The presence of such a loop allows us to take advantage of the frequent formation of RNA loops in cells and their possible interaction with the corresponding Toll-like receptor interacting with single-stranded RNA. Only adenines, cytosines, and guanines are present in the construct, which makes it possible to activate pattern recognition receptors interacting with both 'non-self' DNA and 'non-self' RNA. Since the PS backbone is the basis of the construct, the presence of deoxyribose will be of little importance and everything will depend on the nucletide sequence of the construct [98]. CpG motifs in nuclease-resistant PS backbones have been found to dramatically enhance B cell stimulatory properties $[105,106]$. In almost all vertebrates, the optimal PS CpG ODN are extraordinarily strong mitogens for B cells [107-110]. While the inhibitory effect observed for poly $G$ motifs of $\mathrm{CpG}$ ODN reduces the level of $\mathrm{B}$ cell activation [111], in our construct, this motif is found in the doublestranded 'neck' and may have a positive inhibitory effect during possible acute inflammation that occurs after vaccination. As the body temperature rises, the double-stranded DNA 'neck' melts to produce a single-stranded oligonucleotide sequence containing two poly G motifs. Of note, in vertebrate genomes, $\mathrm{CpG}$ dinucleotides occur only 25\% as frequently as would be predicted if base utilization were random [112]. Furthermore, the bases flanking CpGs in vertebrate genomes are not random: the most common base preceding a $\mathrm{CpG}$ is a $\mathrm{C}$ and the most common base following a $\mathrm{CpG}$ is a $\mathrm{G}$ [113]. These types of $\mathrm{CpG}$ motifs do not support strong immune stimulation. In addition to these differences in $\mathrm{CpG}$ content, methylation of $\mathrm{CpG}$ dinucleotides differs between virus and host. These dinucleotides, which are not methylated in the pathogen DNA, are routinely methylated in vertebrate DNA at the 5 th position of $\sim 70 \%$ of the cytosines [112]. If immune recognition of CpG DNA has evolved as an effective defense, then it seems likely that pathogens would evolve counter strategies to block or evade the defense. One potential strategy would be for a pathogen to reduce the level of $\mathrm{CpG}$ in its genome to decrease its immune-stimulatory effects. In principle, this should be much easier for pathogens having small genomes and many of them were shown to have very low $\mathrm{CpG}$ content $[114,115]$.

Thus, in the proposed construct, the $\mathrm{CpG}$ 'tail' will trigger cells that express Toll-like receptor 9 (including human plasmacytoid dendritic cells and B cells) to mount an innate immune response characterized by the production of $\mathrm{T}$ helper cells 1 and pro-inflammatory cytokines, which will improve the function of the professional antigen-presenting cells and boost the generation of humoral and cellular vaccine-specific immune responses. Also $\mathrm{CpG}$ 'tail' is supposed to trigger Toll-like receptors that interact with the single-stranded RNA containing $\mathrm{CpG}$ motif in a manner similar to interactions with TLR9-CpG ODN. Generally, the unmodified 'tail' will serve as an adjuvant and will prepare the immune system for the meeting with the antigen found on the 'head'. The sequence of the 'head' (5'-GCAGAGACA GAAGAAACAGCAAAC-3') is well conserved. It is found in every SARS-CoV-2 genome located in GenBank at this moment and belongs to a nucleocapsid phosphoprotein gene [protein_id="QJC2104QJC21049.1") that has 87\% query cover with Homo sapiens protein kinase $\mathrm{C}$ eta (PRKCH) (NG_011514.1). 9.1] that has 87\% query cover with Homo sapiens protein kinase $\mathrm{C}$ eta (PRKCH) (NG_011514.1).

Summing up, the proposed design contains $\mathrm{CpG}$ dinucleotides, important for in the activation of innate immunity, and a unique genomic sequence of the virus, the antigenpresenting component that activates adaptive immunity. Similar vaccine constructs based on phosphorothioate oligonucleotides can have a wide variety of unique sequences based on the circulating SARS-CoV-2 strains, and each vaccine may contain a dozen of these lasso-like constructs. In the very near future, we plan to test such vaccines on the murine coronavirus, taking care not to miss any possible negative effects, and remaining aware that the PS backbone dramatically increases the non-specific ODN binding to a wide variety of proteins $[116,117]$. 
The mechanisms of the 'cytokine storm' and how they contribute to fatalities reported for COVID-19 are still under investigation. Currently, it is believed that SARS-CoV-2 dampens antiviral interferon responses, which results in uncontrolled viral replication. For the other coronaviruses, SARS-CoV and MERS-CoV, the response to viral infection by type I IFN is suppressed. The influx of neutrophils and monocytes/macrophages results in hyperproduction of proinflammatory cytokines [118]. In a study of 41 patients hospitalized with COVID-19, high levels of pro-inflammatory cytokines were found, including IL-2, IL-7, G-CSF, IP-10, MCP-1, MIP-1A, and TNF- $\alpha$, in the most severe cases [119]. This overproduction of a large number of pro-inflammatory cytokines dubbed a 'cytokine storm,' begins a cascade of events that is hard to stop. For instance, the cytokine storm can initiate viral sepsis and inflammatory-induced lung injury, which leads to other complications including pneumonitis. While 'cytokine storms' can overwhelm people of any age, some scientists believe that this phenomenon may explain why otherwise healthy young people died during the 1918 Spanish flu pandemic and more recently during the SARS, MERS, and H1N1 epidemics. One of the most frequently studied organisms known to cause cytokine storms is influenza a virus, particularly the pandemic subtypes. It has been shown that the H1N1 strain responsible for the 1918 pandemic induced higher levels of pro-inflammatory immune cells and cytokines in the lungs than the seasonal influenza viruses. This contributed to its high virulence and may account for the unusually high mortality rate seen among young adults during the outbreak [120]. Severe influenza infections caused by highly virulent subtypes such $\mathrm{H} 1 \mathrm{~N} 1$ and $\mathrm{H} 5 \mathrm{~N} 1$ are characterized by over induction of the pro-inflammatory cytokines TNF- $\alpha$, IL-1 $\beta$, IL-6, IL-8, and monocyte chemoattractant protein-1 (MCP-1) [121, 122], which eventually results in multiple organ dysfunction and failure and increased vascular hyperpermeability [122].

With respect to the tendency of the body to overexpress cytokines and let loose a 'cytokine storm' during coronavirus infection in some humans, we are proposing vaccine construct having the CpG motifs which will help people's immune systems train for this inflammation reaction in the absence of a real pathogen and real danger. In a broad sense, the immune system copes with the virus much more effectively if it has already encountered it. The unmethylated $\mathrm{CpG}$ motif is certainly that portion of the virus genome for which the immune system of sensitive people needs to be prepared. Generally, CpG ODN boosted the humoral immune response induced by vaccines against a large number of pathogens, including influenza virus, measles virus, lymphocytic choriomeningitis virus, orthopoxviruses, and other viruses [71]. At the height of the epidemic, when more than 500,000 people have already died, apparently it is time to try this approach when creating a vaccine against
SARS-CoV-2. Even though SARS-CoV-2 will constantly sweep its tracks, an effective vaccine should contain a $\mathrm{CpG}$ motif as a conservative fingerprint of the pathogen to train the human immune response. The fight against COVID-19 will be difficult and lengthy. Nevertheless, the current situation will help to gain experience and the ability to prevent future coronavirus pandemics. Life goes on.

Acknowledgements This work was supported by state program No FZEG-2020-0060 of the Ministry of Science and Higher Education of Russian Federation.

\section{References}

1. Andersen KG, Rambaut A, Lipkin WI, et al. The proximal origin of SARS-CoV-2. Nat Med. 2020;26:450-2.

2. Koup RA, Douek DC. Vaccine design for CD8 T lymphocyte responses. Cold Spring Harb Perspect Med. 2011;1:a007252.

3. Kenney RT, Cross AS. Adjuvants for the future. In: Levine MM, Dougan G, Good MF, Liu MA, Nabel GJ, Nataro JP, Rappuoli R, editors. New Generation Vaccines. New York: Informa Healthcare USA, Inc.; 2010. p. 250-262.

4. Pulendran B, Powell J, Flavell RA. Modulating vaccine responses with innate immunity. In: Levine MM, Dougan G, Good MF, Liu MA, Nabel GJ, Nataro JP, Rappuoli R, editors. New Generation Vaccines. New York: Informa Healthcare USA, Inc.; 2010. p. 183-190.

5. Paltrinieri S, Cammarata MP, Cammarata G, Comazzi S. Some aspects of humoral and cellular immunity in naturally occuring feline infectious peritonitis. Vet Immunol Immunopathol. 1998;65:205-20.

6. Loa CC, Lin TL, Wu CC, Bryan T, Thacker HL, Hooper T, Schrader D. Humoral and cellular immune responses in turkey poults infected with turkey coronavirus. Poult Sci. 2001;80:1416-24.

7. He Y, Jiang S. Vaccine design for severe acute respiratory syndrome coronavirus. Viral Immunol. 2005;18:327-32.

8. Lin JT, Zhang JS, Su N, Xu JG, Wang N, Chen JT, Chen X, Liu YX, Gao H, Jia YP. Safety and immunogenicity from a phase I trial of inactivated severe acute respiratory syndrome coronavirus vaccine. Antivir Ther (Lond). 2007;12:1107-13.

9. Martin JE, Louder MK, Holman LA, Gordon IJ, Enama ME, Larkin BD, Andrews CA, Vogel L, Koup RA, Roederer M. VRC 301 Study Team A SARS DNA vaccine induces neutralizing antibody and cellular immune responses in healthy adults in a Phase I clinical trial. Vaccine. 2008;26:6338-433.

10. Lan L, Xu D, Ye G, Xia C, Wang S, Li Y, Xu H. Positive RTPCR test results in patients recovered from COVID-19. JAMA. 2020;323(15):1502-3.

11. Wrapp D, Wang N, Corbett KS, Goldsmith JA, Hsieh CL, Abiona O, Graham BS, McLellan JS. Cryo-EM structure of the 2019-nCoV spike in the prefusion conformation. Science. 2020;367:1260-3.

12. ter Meulen J, van den Brink EN, Poon LL, Marissen WE, Leung CS, Cox F, Cheung CY, Bakker AQ, Bogaards JA, van Deventer E. Human monoclonal antibody combination against SARS coronavirus: synergy and coverage of escape mutants. PLoS Med. 2006;3:e237.

13. Tian X, Li C, Huang A, Xia S, Lu S, Shi Z, Lu L, Jiang S, Yang Z, Wu Y, Ying T. Potent binding of 2019 novel coronavirus 
spike protein by a SARS coronavirus-specific human monoclonal antibody. Emerg Microbes Infect. 2020;9:382-5.

14. Pallesen J, Wang N, Corbett KS, Wrapp D, Kirchdoerfer RN, Turner HL, Cottrell CA, Becker MM, Wang L, Shi W. Immunogenicity and structures of a rationally designed prefusion MERS-CoV spike antigen. Proc Natl Acad Sci USA. 2017;114:E7348-E73577357.

15. Wong S-S, Webby RJ. Traditional and new influenza vaccines. Clin Microbiol Rev. 2013;26:476-92.

16. Ran Z, Shen H, Lang Y, Kolb EA, Turan N, Zhu L, et al. Domestic pigs are susceptible to infection with influenza B viruses. J Virol. 2015;89(9):4818-26.

17. Heo JY, Song JY, Noh JY, Choi MJ, Yoon JG, Lee SN, Cheong HJ, Kim WJ. Effects of influenza immunization on pneumonia in the elderly. Hum Vacc Immuno. 2017;1:744-9.

18. Siriwardena AN. Increasing evidence that influenza is a trigger for cardiovascular disease. J Infect Dis. 2012;206:1636-8.

19. Sridhar S, Brokstad KA, Cox RJ. Influenza Vaccination Strategies: Comparing Inactivated and Live Attenuated Influenza Vaccines. Vaccines (Basel). 2015;3(2):373-89.

20. Isakova-Sivak I, Rudenko L. Safety, immunogenicity and infectivity of new live attenuated influenza vaccines. Expert Rev Vaccines. 2015;14(10):1313-29.

21. Types of seasonal influenza vaccine. World Health Organ.https ://www.euro.who.int/en/health-topics/communicable-diseases/ influenza/vaccination/types-of-seasonal-influenza-vaccine. Accessed 5 May 2020.

22. Uchida T. Development of a cytotoxic T-lymphocyte-based, broadly protective influenza vaccine. Microbiol Immunol. 2011;55:19-27.

23. Li R, Stewart B, McNeil MM, Duffy J, Nelson J, Kawai AT, Baxter R, Belongia EA, Weintraub E. Post licensure surveillance of influenza vaccines in the Vaccine Safety Datalink in the 2013-2014 and 2014-2015 seasons. Pharmacoepidemiol Drug Saf. 2016;25(8):928-34.

24. Sarkanen TO, Alakuijala APE, Dauvilliers YA, Partinen MM. Incidence of narcolepsy after H1N1 influenza and vaccinations: systematic review and meta-analysis. Sleep Med Rev. 2017; 17:30001-11.

25. Trombetta CM, Montomoli E. Influenza immunology evaluation and correlates of protection: a focus on vaccines. Expert Rev Vaccines. 2016;15:967-76.

26. El Zowalaty ME, Järhult JD. From SARS to COVID-19: a previously unknown SARS-CoV-2 virus of pandemic potential infecting humans-Call for a One Health approach. One Health. 2020;10:1-24

27. Parrish CR, Murcia PR, Holmes EC. Influenza virus reservoirs and intermediate hosts: dogs, horses, and new possibilities for influenza virus exposure of humans. J Virol. 2015;89(6):2990-4.

28. Luciw PA. Human immunodeficiency viruses and their replication. In: Fields BN, editor. Virology. 3rd ed. Philadelphia: Lippincott-Raven; 1996. p. 1881-1952.

29. Sharp PM, Hahn BH. Origins of HIV and the AIDS pandemic Cold spring Harbor perspectives in medicine. Medicine. 2011;6:8-41.

30. Kwong PD, Wyatt R, Robinson J, Sweet RW, Sodroski J, Hendrickson WA. Structure of an HIV gp120 envelope glycoprotein in complex with the CD4 receptor and a neutralizing human antibody. Nature. 1994;4(393):648-59.

31. Myszka DG, Sweet RW, Hensley P, Brigham-Burke M, Kwong PD, Hendrickson WA, Wyatt R, Sodroski J, Doyle ML. Energetics of the HIV gp120-CD4 binding reaction. Proc Natl Acad Sci USA. 2000;97:9026-31.

32. Finzi D, Siliciano RF. Viral dynamics in HIV-1 infection. Cell. 1998;93:665-71.
33. Overbaugh J, Morris L. The antibody response against HIV-1 Cold Spring Harb. Perspect Med. 2012;2:7-39.

34. Brown BK, Wieczorek L, Sanders-Buell E, Rosa Borges A, Robb ML, Birx DL, Michael NL, McCutchan FE, Polonis VR. Crossclade neutralization patterns among HIV-1 strains from the six major clades of the pandemic evaluated and compared in two different models. Virology. 2008;375:529-38.

35. Dreja H, O'Sullivan E, Pade C, Greene KM, Gao H, Aubin K, Hand J, Isaksen A, D'Souza C, Leber W, et al. Neutralization activity in a geographically diverse East London cohort of human immunodeficiency virus type 1-infected patients: Clade $\mathrm{C}$ infection results in a stronger and broader humoral immune response than clade B infection. J Gen Virol. 2010;91:2794-803.

36. Preston BD. Reverse transcriptase fidelity and HIV-1 variation. Science. 1997;275:228-9.

37. Ho DD, Neumann AU, Perelson AS, Chen W, Leonard JM, Markowitz M. Rapid turnover of plasma virions and CD4 lymphocytes in HIV-1 infection. Nature. 1995;373:123-6.

38. Evans DT, O'Connor DH, Jing P, Dzuris JL, Sidney J, da Silva J, Allen TM, Horton H, Venham JE, Rudersdorf JA, Vogel T, Pauza CD, Bontrop RE, DeMars R, Sette A, Hughes AL, Watkins DI. Virus-specific cytotoxic T-lymphocyte responses select for amino-acid variation in simian immunodeficiency virus. Env Nef Nat Med. 1999;5:1270-6.

39. Parren PW, Moore JP, Burton DR, Sattentau QJ. The neutralizing antibody response to HIV-1: viral evasion and escape from humoral immunity. AIDS. 1999;13:137-62.

40. Korber B, Gaschen B, Yusim K, Thakallapally R, Kesmir C, Detours V. Evolutionary and immunological implications of contemporary HIV-1 variation. Br Med Bull. 2001;58:19-42.

41. McCutchan FE. Understanding the genetic diversity of HIV-1. AIDS. 2000;14(3):31-44.

42. Forns X, Bukh J, Purcell RH. The challenge of developing a vaccine against hepatitis C virus. J Hepatol. 2002;37:684-95.

43. Pybus OG, Theze J. Hepacivirus cross-species transmission and the origins of the hepatitis $\mathrm{C}$ virus. Curr Opin Virol. 2006;16:1-7.

44. Drexler JF, Corman VM, Müller MA, Lukashev AN, Gmyl A, Coutard B, Adam A, Ritz D, Leijten LM, van Riel D, Kallies R, Klose SM, Gloza-Rausch F, Binger T, Annan A, Adu-Sarkodie Y, Oppong S, Bourgarel M, Rupp D, Hoffmann B, Schlegel M, Kümmerer BM, Krüger DH, Schmidt-Chanasit J, Setién AA, Cottontail VM, Hemachudha T, Wacharapluesadee S, Osterrieder K, Bartenschlager R, Matthee S, Beer M, Kuiken T, Reusken C, Leroy EM, Ulrich RG, Drosten C. Evidence for novel hepaciviruses in rodents. PLoS Pathog. 2013;9:e1003438.

45. Baechlein C, Fischer N, Grundhoff A, et al. Identification of a Novel Hepacivirus in Domestic Cattle from Germany. J Virol. 2015;89(14):7007-155.

46. Lauck M, Sibley SD, Lara J, Purdy MA, Khudyakov Y, Hyeroba $\mathrm{D}$, et al. A novel hepacivirus with an unusually long and intrinsically disordered NS5A protein in a wild Old World primate. J of Virol. 2013;87:8971-81.

47. Pawlotsky JM, Feld JJ, Zeuzem S, Hoofnagle JH. From non-A, non-B hepatitis to hepatitis $\mathrm{C}$ virus cure. J Hepatol. 2015;62:87-99.

48. Falade-Nwulia O, Suarez-Cuervo C, Nelson DR, Fried MW, Segal JB, Sulkowski MS. Oral direct-acting agent therapy for hepatitis $\mathrm{C}$ virus infection: a systematic review. Ann Intern Med. 2017;166(9):637-48.

49. WHO. Global Hepatitis Report Geneva. Switzerland: WHO; 2017.

50. Gravitz L. Introduction: a smouldering public-health crisis. Nature. 2011;474:2-4.

51. Cox AL. MEDICINE. Global control of hepatitis C virus. Science. 2015;349:790-1. 
52. Falade-Nwulia O, Sulkowski MS, Merkow A, Latkin C, Mehta SH. Understanding and addressing hepatitis $\mathrm{C}$ reinfection in the oral direct-acting antiviral era. J Viral Hepat. 2018;25:220-7.

53. Frey SE, Houghton M, Coates S, Abrignani S, Chien D, Rosa D, et al. Safety and immunogenicity of HCV E1E2 vaccine adjuvanted with MF59 administered to healthy adults. Vaccine. 2010;28:6367-73.

54. Law JL, Chen C, Wong J, Hockman D, Santer DM, Frey SE, et al. A hepatitis $\mathrm{C}$ virus (HCV) vaccine comprising envelope glycoproteins gpE1/gpE2 derived from a single isolate elicits broad cross-genotype neutralizing antibodies in humans. PLoS ONE. 2013;8:e59776.

55. Shoukry NH, Hepatitis C. Vaccines, antibodies, and T Cells. Front Immunol. 2018;9:9.

56. Abdel-Hakeem MS, Shoukry NH. Protective immunity against hepatitis C: many shades of gray. Front Immunol. 2014;5:274.

57. Badr G, Bedard N, Abdel-Hakeem MS, Trautmann L, Willems B, Villeneuve JP, et al. Early interferon therapy for hepatitis $\mathrm{C}$ virus infection rescues polyfunctional, long-lived CD8+ memory T cells. J Virol. 2008;82:5.

58. Golden-Mason L, Burton JR Jr, Castelblanco N, Klarquist J, Benlloch S, Wang C, et al. Loss of IL-7 receptor alpha-chain (CD127) expression in acute HCV infection associated with viral persistence. Hepatology. 2006;44:1098-109. https://doi. org/10.1002/hep.21365.

59. Bengsch B, Spangenberg HC, Kersting N, Neumann-Haefelin C, Panther E, Von Weizsacker F, et al. Analysis of CD127 and KLRG1 expression on hepatitis C virus-specific CD8+ T cells reveals the existence of different memory $\mathrm{T}$-cell subsets in the peripheral blood and liver. J Virol. 2007;81:945-53.

60. Shin EC, Park SH, Nascimbeni M, Major M, Caggiari L, De Re V, et al. The frequency of CD127+ HCV-specific T cells but not the expression of exhaustion markers predict the outcome of acute hepatitis $\mathrm{C}$ virus infection. J Virol. 2013;87(8):4772-7.

61. Gupta PK, Godec J, Wolski D, Adland E, Yates K, Pauken KE, et al. CD39 expression identifies terminally exhausted CD8+ T cells. PLoS Pathog. 2015;11:e1005177.

62. Ball JK, Tarr AW, McKeating JA. The past, present and future of neutralizing antibodies for hepatitis $\mathrm{C}$ virus. Antiviral Res. 2014;105(100):100-11.

63. Law M, Maruyama T, Lewis J, Giang E, Tarr AW, Stamataki Z, et al. Broadly neutralizing antibodies protect against hepatitis $\mathrm{C}$ virus quasispecies challenge. Nat Med. 2008;14:25-7.

64. Giang E, Dorner M, Prentoe JC, Dreux M, Evans MJ, Bukh J, et al. Human broadly neutralizing antibodies to the envelope glycoprotein complex of hepatitis C virus. Proc Natl Acad Sci USA. 2012;109:6205-10.

65. Bailey JR, Flyak AI, Cohen VJ, Li H, Wasilewski LN, Snider AE, et al. Broadly neutralizing antibodies with few somatic mutations and hepatitis C virus clearance. JCI Insight. 2017;2(9):e92872.

66. Batista-Duharte A, Sendra L, Herrero MJ, Téllez-Martínez D, Carlos IZ, Aliño SF. Progress in the Use of Antisense Oligonucleotides for Vaccine Improvement. Biomolecules. 2020;10(2):316.

67. Myhr AI. DNA Vaccines: regulatory considerations and safety aspects. Curr Issues Mol Biol. 2017;22:79-88.

68. Ghaffarifar F. Plasmid DNA vaccines: where are we now? Drugs Today Barc. 2018;54:315-33.

69. Geall AJ, Mandl CW, Ulmer JB. RNA: the new revolution in nucleic acid vaccines. Semin Immunol. 2013;25:152-9.

70. Kramps T, Elbers K. Introduction to RNA vaccines. Methods Mol Biol. 2017;1499:1-11.

71. Bode C, Zhao G, Steinhagen F, Kinjo T, Klinman DM. CpG DNA as a vaccine adjuvant. Expert Rev Vaccines. 2011;10:499-511.
72. Scheiermann J, Klinman DM. Clinical evaluation of CpG oligonucleotides as adjuvants for vaccines targeting infectious diseases and cancer. Vaccine. 2014;32:6377-89.

73. Yamamoto S, Yamamoto T, Shimada S, Kuramoto E, Yano O, Kataoka T, Tokunaga T. DNA from bacteria, but not from vertebrates, induces interferons, activates natural killer cells and inhibits tumor growth. Microbiol Immunol. 1992;36:983-97.

74. Krieg AM, Yi AK, Matson S, Waldschmidt TJ, Bishop GA, Teasdale R, Koretzky GA, Klinman DM. CpG motifs in bacterial DNA trigger direct B-cell activation. Nature. 1995;374:546-9.

75. Janeway CA, Medzhitov R. Innate immune recognition. Annu Rev Immunol. 2020;20:197-21616.

76. Murad YM, Clay TM. CpG Oligodeoxynucleotides as TLR9 Agonists. BioDrugs. 2009;23:361-75.

77. Vollmer J, Krieg AM. Immunotherapeutic applications of $\mathrm{CpG}$ oligodeoxynucleotide TLR9 agonists. Adv Drug Deliv Rev. 2009;61:195-204.

78. Campbell JD. Development of the $\mathrm{CpG}$ adjuvant 1018: a case study. Methods Mol Biol. 2017;1494:15-27.

79. Guerrier T, Youinou P, Pers JO, Jamin C. TLR9 drives the development of transitional B cells towards the marginal zone pathway and promotes autoimmunity. J Autoimmun. 2012;39:173-9.

80. Sacher T, Knolle P, Nichterlein T, Arnold B, Hämmerling GJ, Limmer A. CpG-ODN-induced inflammation is sufficient to cause T-cell-mediated autoaggression against hepatocytes. Eur J Immunol. 2002;32:3628-37.

81. Channappanavar R, Zhao J, Perlman S. T cell-mediated immune response to respiratory coronaviruses. Immunol Res. 2014;59(1-3):118-28.

82. Peiris JS, Guan Y, Yuen KY. Severe acute respiratory syndrome. Nat Med. 2004;10:S88-S97.

83. Murasko DM, Jiang J. Response of aged mice to primary virus infections. Immunol Rev. 2005;205:285-96.

84. Gardner EM, Gonzalez EW, Nogusa S, Murasko DM. Agerelated changes in the immune response to influenza vaccination in a racially diverse, healthy elderly population. Vaccine. 2006;24:1609-14.

85. Roberts A, Deming D, Paddock CD, Cheng A, Yount B, Vogel L, Herman BD, Sheahan T, Heise M, Genrich GL, Zaki SR, Baric $\mathrm{R}$, Subbarao K. A mouse-adapted SARS-coronavirus causes disease and mortality in BALB/c mice. PLoS Pathog. 2007;3:e5.

86. Williamson JS, Stohlman SA. Effective clearance of mouse hepatitis virus from the central nervous system requires both CD4+ and CD8+ T cells. J Virol. 1990;64:4589-92.

87. Roth Y, Chapnik JS, Cole P. Feasibility of aerosol vaccination in humans. Ann Otol Rhinol Laryngol. 2003;112:264-70.

88. Manjaly Thomas ZR, McShane H. Aerosol immunisation for TB: matching route of vaccination to route of infection. Trans R Soc Trop Med Hyg. 2015;109:175-81.

89. Hodgson J. The pandemic pipeline. Nat Biotechnol. 2020;4:8.

90. Gottlieb J, Zamora MR, Hodges T, Musk AW, Sommerwerk U, Dilling D, Arcasoy S, DeVincenzo J, Karsten V, Shah S, et al. ALN-RSV01 for prevention of bronchiolitis obliterans syndrome after respiratory syncytial virus infection in lung transplant recipients. J Heart Lung Transplant. 2016;35:213-21.

91. Latz E, Schoenemeyer A, Visintin A, Fitzgerald KA, Monks BG, Knetter CF, Lien E, Nilsen NJ, Espevik T, Golenbock DT. TLR9 signals after translocating from the ER to CpG DNA in the lysosome. Nat Immunol. 2004;5:190-8.

92. Yasuda K, Yu P, Kirschning CJ, Schlatter B, Schmitz F, Heit A, Bauer S, Hochrein H, Wagner H. Endosomal translocation of vertebrate DNA activates dendritic cells via TLR9-dependent and -independent pathways. J Immunol. 2005;174:6129-36.

93. Haas T, Metzger J, Schmitz F, Heit A, Muller T, Latz E, Wagner $\mathrm{H}$. The DNA sugar backbone 2 ' deoxyribose determines toll-like receptor 9 activation. Immunity. 2008;28:315-23. 
94. Wagner H. The sweetness of the DNA backbone drives Toll-like receptor 9. Curr Opin Immunol. 2008;20:396-400.

95. Ashman RF, Goeken JA, Latz E, Lenert P. Optimal oligonucleotide sequences for TLR9 inhibitory activity in human cells: lack of correlation with TLR9 binding. Int Immunol. 2011;23:203-14.

96. Glasspool-Malone J, Steenland PR, McDonald RJ, Sanchez RA, Watts TL, Zabner J, Malone RW. DNA transfection of macaque and murine respiratory tissue is greatly enhanced by use of a nuclease inhibitor. J Gene Med. 2002;4:323-32.

97. Dias N, Stein CA. Antisense oligonucleotides: basic concepts and mechanisms. Mol Cancer Ther. 2002;1:347-55.

98. Haas T, et al. The DNA sugar backbone 2 ' deoxyribose determines toll-like receptor 9 activation. Immunity. 2008;28:315-23.

99. Atkinson NJ, Witteveldt J, Evans DJ, Simmonds P. The influence of $\mathrm{CpG}$ and $\mathrm{UpA}$ dinucleotide frequencies on RNA virus replication and characterization of the innate cellular pathways underlying virus attenuation and enhanced replication. Nucleic Acids Res. 2014;42:4527-45.

100. Greenbaum BD, Rabadan R, Levine AJ. Patterns of oligonucleotide sequences in viral and host cell RNA identify mediators of the host innate immune system. PLoS ONE. 2009;4(6):e5969.

101. Lobo FP, Mota BE, Pena SD, Azevedo V, Macedo AM, Tauch A, Machado CR, Franco GR. Virus-host coevolution: common patterns of nucleotide motif usage in Flaviviridae and their hosts. PLoS ONE. 2009;4(7):e6282.

102. Greenbaum BD, Levine AJ, Bhanot G, Rabadan R. Patterns of evolution and host gene mimicry in influenza and other RNA viruses. PLoS Pathog. 2008;4:e1000079.

103. Jimenez-Baranda S, Greenbaum B, Manches O, Handler J, Rabadán R, et al. Oligonucleotide motifs that disappear during the evolution of influenza virus in humans increase alpha interferon secretion by plasmacytoid dendritic cells. J Virol. 2011;85:3893-904.

104. Krieg AM, Wagner H. Causing a commotion in the blood: immunotherapy progresses from bacteria to bacterial DNA. Immunol Today. 2000;21:521-6.

105. Ballas ZK, Rasmussen WL, Krieg AM. Induction of NK activity in murine and human cells by $\mathrm{CpG}$ motifs in oligodeoxynucleotides and bacterial DNA. J Immunol. 1996;157(5):1840-5.

106. Yamamoto S, Yamamoto T, Kataoka T, Kuramoto E, Yano O, Tokunaga T. Unique palindromic sequences in synthetic oligonucleotides are required to induce IFN [correction of INF] and augment IFN-mediated [correction of INF] natural killer activity. J Immunol. 1992;148(12):4072-6.

107. Rankin R, Pontarollo R, Iannou X, Krieg AM, Hecker R. CpG motif identification for veterinary and laboratory species demonstrates that sequence recognition is highly conserved. Antisense Nucleic Acid Drug Dev. 2001;11:333-40.

108. Hartmann G, Krieg AM. Mechanism and function of a newly identified CpG DNA motif in human primary B cells. J Immunol. 2000;164(2):944-53.
109. Hartmann G, Weeratna RD, Ballas ZK, Payette P, Blackwell S, Suparto I, Rasmussen WL, Waldschmidt M, Sajuthi D, Purcell $\mathrm{H}$, Davis HL, Krieg AM. Delineation of a CpG phosphorothioate oligodeoxynucleotide for activating primate immune responses in vitro and in vivo. J Immunol. 2000;164(3):1617-24.

110. Liang H, Nishioka Y, Reich CF, Pisetsky DS, Lipsky PE. Activation of human B cells by phosphorothioate oligodeoxynucleotides. J Clin Invest. 1996;98(5):1119-29.

111. Krieg AM. CpG Motifs in Bacterial DNA and Their Immune Effects. Ann Rev Immunol. 2002;20:709-60.

112. Bird AP. CpG islands as gene markers in the vertebrate nucleus. Trends Genet. 1987;3:342-7.

113. Han J, Zhu Z, Hsu C, Finley WH. Selection of antisense oligonucleotides on the basis of genomic frequency of the target sequence. Antisense Res Dev. 1994;4(1):53-655.

114. Shpaer EG, Mullins JI. Selection against CpG dinucleotides in lentiviral genes: a possible role of methylation in regulation of viral expression. Nucleic Acids Res. 1990;18(19):5793-7.

115. Krieg AM. Lymphocyte activation by $\mathrm{CpG}$ dinucleotide motifs in prokaryotic DNA. Trends Microbiol. 1996;4(2):73-6.

116. Stein CA, Cheng YC. Antisense oligonucleotides as therapeutic agents-is the bullet really magical? Science. 1993;261(5124):1004-122.

117. Stein CA, Krieg AM. Problems in interpretation of data derived from in vitro and in vivo use of antisense oligodeoxynucleotides [editorial]. Antisense Res Dev. 1994;4(2):67-9.

118. Prompetchara E, Ketloy C, Palaga T. Immune responses in COVID-19 and potential vaccines: Lessons learned from SARS and MERS epidemic. Asian Pac J Allergy Immunol. 2020;38(1):1-9.

119. Huang C, Wang Y, Li X, et al. Clinical features of patients infected with 2019 novel coronavirus in Wuhan. China Lancet. 2020;395:497-506.

120. Perrone LA, Plowden JK, Garcia-Sastre A, Katz JM, Tumpey TM. H5N1 and 1918 pandemic influenza virus infection results in early and excessive infiltration of macrophages and neutrophils in the lungs of mice. PLoS Pathog. 2008;4:e1000115.

121. Wang SY, Le TQ, Kurihara N, Chida J, Cisse Y, Yano M, Kido $\mathrm{H}$. Influenza virus-cytokine-protease cycle in the pathogenesis of vascular hyperpermeability in severe influenza. J Infect Dis. 2010;202:991-1001.

122. Cheng XW, Lu JA, Wu CL, Yi LN, Xie X, Shi XD, Fang SS, Zan H, Kung HF, He ML. Three fatal cases of pandemic 2009 influenza A virus infection in Shenzhen are associated with cytokine storm. Respir Physiol Neurobiol. 2011;175:185-7.

Publisher's Note Springer Nature remains neutral with regard to jurisdictional claims in published maps and institutional affiliations. 